\title{
Association between hemorrhagic stroke occurrence and meteorological factors and pollutants
}

\author{
Myung-Hoon Han ${ }^{1}$, Hyeong-Joong $\mathrm{Yi}^{1^{*}}$, Yong Ko ${ }^{1}$, Young-Soo Kim ${ }^{1}$ and Young-Jun Lee ${ }^{2}$
}

\begin{abstract}
Background: The purpose of this study is to determine whether intracerebral hemorrhage and subarachnoid hemorrhage have different incidence patterns based on monthly variations in meteorological and air pollution parameters in the Seongdong district of Seoul, South Korea.
\end{abstract}

Methods: From January 1, 2004 to December 31, 2014, 1,477 consecutive hemorrhagic stroke events (>19 years old) were registered among residents of the Seongdong district, Seoul, South Korea. The authors calculated the relative risk of hemorrhagic stroke and its subtype incidence based on meteorological and air pollution factors. We also estimated relative risk with $95 \%$ confidence intervals using a multivariate Poisson regression model to identify potential independent variables among meteorological factors and pollutants associated with either intracerebral hemorrhage or subarachnoid hemorrhage occurrence.

Results: We observed a negative correlation between intracerebral hemorrhage and mean temperature. In the multivariate Poisson model, particulate matter with an aerodynamic diameter $<10 \mu \mathrm{m}$ showed positive correlations with intracerebral hemorrhage (relative risk, 1.09; $95 \%$ confidence interval, 1.02 to 1.15; $P=0.012$ ). In contrast, ozone correlated significantly with subarachnoid hemorrhage occurrence (relative risk, 1.32; $95 \%$ confidence interval, 1.10 to $1.58 ; P=0.003$ ).

Conclusions: Our findings show the relationship between hemorrhagic stroke and meteorological parameters and pollutants under similar weather and environmental conditions in a small area. Among meteorological and pollutant variables, only higher particulate matter concentrations correlated independently with intracerebral hemorrhage occurrence, while only ozone was independently associated with subarachnoid hemorrhage occurrence. These findings suggest the possibility that there are pathogenic associations between hemorrhagic stroke and meteorological factors and pollutants.

Keywords: Hemorrhagic stroke, Intracerebral hemorrhage, Subarachnoid hemorrhage, Weather, Air pollution

\section{Background}

Hemorrhagic stroke (HS) is a major cause of mortality and disability in neurosurgical practice. Asian people have a higher incidence of HS, compared to those in the United States and European countries [1, 2]. Many studies have linked meteorological factors or concentrations of air pollutants with ischemic stroke. Nevertheless, the association of these factors with HS remains

\footnotetext{
* Correspondence: hjyi8499@hanyang.ac.kr

${ }^{1}$ Department of Neurosurgery, Hanyang University Medical Center, 222

Haengdang-ro, Seoul 133-792, South Korea

Full list of author information is available at the end of the article
}

inconsistent. In addition, few studies have provided findings on associations with subarachnoid hemorrhage (SAH). SAH and intracerebral hemorrhage (ICH) are two subtypes of hemorrhagic stroke. ICH results from rupture of small penetrating arteries deep in the brain, and SAH occurs secondary to aneurysm rupture in the relatively large subarachnoid space.

Most studies [1, 3-10] have agreed that the incidence of $\mathrm{ICH}$ increases at lower temperatures or during colder seasons, and several studies [11-15] reported the positive association between HS incidence and pollutants. However, there have been inconsistencies and a lack of 
information on the relationship between meteorological factors and pollutants and SAH incidence.

We sought to demonstrate the association between HS occurrence and monthly variations in meteorological and air pollution parameters stratified by sex and age group under similar weather and environmental conditions in a small area over the 11-year study period. We hope to ascertain whether ICH and SAH have different incidence patterns based on variations in meteorological and air pollution parameters.

\section{Methods}

\section{Study area}

Hanyang University Medical Center is the sole regional tertiary hospital qualified to treat stroke in the Seongdong district of Seoul, South Korea. We previously reported the characteristics of the Seongdong district [16]. Patients within the study area can reach the Hanyang University Medical Center emergency unit within $15 \mathrm{~min}$ by car, and almost all emergent patients within the Seongdong district are obligated to be transported to our hospital according to the guidelines of the Emergency Medical Services system. According to Seongdong Statistical Analysis (http://st.sd.go.kr), the population of the Seongdong district remained stable during the 11-year study period. In addition, it is a community of inhabitants who are mainly classified into a single cultural subgroup with similar standards of living.

\section{Cases}

We collected patient data retrospectively from our hospital's HS registry, which was designed for prospective research for various purposes, between January 1, 2004 and December 31, 2014. According to our hospital protocol, all HS patients are obligated to be admitted to the department of neurosurgery. We included registered HS patients in the present study who were residents of the Seongdong district, > 19 years of age, with no prior history of HS and no evidence of trauma or brain tumor. Our hospital regards patients as adults from the age of 19. We define 19 years old as the cut-off criteria between children and adult.

HS was defined by discharge diagnoses coded as I60 or I61 according to the International Classification of Diseases, 10th Revision (ICD-10). HS subtypes were designated as follows: SAH, I60 and ICH, I61. If intracerebral hemorrhage (ICH) and $\mathrm{SAH}$ presented together, we classified the hemorrhage according to the major site. There were a total of 1,958 patients were initially enrolled in this study. For our study, 481 patients outside of the study area were excluded. A total of 1,477 consecutive cases were finally included based on the above criteria.
All diagnoses were confirmed by CT or MRI, and all medical records were reviewed by three specialized researchers using an electronic medical record system database.

This study was approved by the Institutional Review Board of Hanyang University Medical Center. Due to the retrospective nature of this study the ethics committee waived the requirement for subsequent written informed consent from the included patients; however, we de-identified and anonymized patient records/information prior to analysis.

\section{Meteorological and air pollution data}

The meteorological variables that were studied included monthly measures of mean temperature, average atmospheric pressure, humidity and insolation in the Seongdong district for the 11-year study period. These data were obtained from the Meteorological Administration of South Korea (http://www.kma.go.kr). For the insolation variable, we obtained data for the monthly total hours of insolation. Then, we divided the total monthly insolation hours by the pertinent number of days to investigate each month's average daily insolation hours for every month for each year of the 11-year study period. Data on pollutants included monthly measures of particulate matter with an aerodynamic diameter $<10 \mu \mathrm{m}\left(\mathrm{PM}_{10}\right)$, nitrogen dioxide $\left(\mathrm{NO}_{2}\right)$ and ozone $\left(\mathrm{O}_{3}\right)$ in the Seongdong district, Seoul for the 11year study period. This data was obtained from the Climate and Air Quality Management Division of South Korea (http://cleanair.seoul.go.kr).

\section{Statistical methods}

Baseline characteristics of patient data were presented as the mean \pm standard deviation and number/percentage. The Chi-square and student $t$-test were used to assess differences between the ICH and SAH groups.

Descriptive statistics was used to describe the average monthly meteorological parameters and air pollution concentrations.

Pearson correlation was used to evaluate the relationships between meteorological and air pollution factors.

Poisson generalized linear regression models were used to model the risk of a patient presenting with stroke by using a log-linkage function offset by the log of the population in each month from 2004 to 2014. Predictor variables used in these models included average monthly temperature, atmospheric pressure, humidity, insolation, $\mathrm{PM}_{10}, \mathrm{NO}_{2}$ and $\mathrm{O}_{3}$. We scaled the relative risk (RR) for temperature in increments of $1{ }^{\circ} \mathrm{C}$, atmospheric pressure in increments of $1 \mathrm{hPa}$, humidity in increments of $5 \%$, insolation in increments of $1 \mathrm{~h}$ and pollutants in increments of $10 \mathrm{mg} / \mathrm{m}^{3}$. Poisson regression models were run for the group as a whole and then 
separately for stroke subtype, sex and age group. In addition, we then estimated RRs with $95 \%$ CIs using a multivariate Poisson regression model to identify potential independent meteorological and pollutant variables associated with either ICH or SAH occurrence.

Statistical analyses were performed using $\mathrm{R}$ version 3.1.2 and SPSS for Windows, version 22.0.

\section{Results}

The total population of the Seongdong district, Seoul was 248,996 (>19 years of age) in 2014 based on the population census of Korea. A total of 1,477 patients $(\mathrm{ICH}, 1,016)$ with $\mathrm{HS}$ were enrolled for final analysis. The average age of HS onset was 57.2 years, and $54.2 \%$ of patients were men. Further descriptive data and history of risk factors are shown in Table 1 . The distribution of average monthly meteorological variables and air pollutants for the 11-year study period is shown in Table 2.

We estimated the pairwise Pearson correlation coefficients ( $r$ ) among meteorological variables and pollutants. The mean temperature showed the strongest negative correlation with atmospheric pressure $(r=-0.824)$, and humidity was negatively associated with insolation $(r=-0.603)$. Additionally, $\mathrm{PM}_{10}$ was observed to correlate with $\mathrm{NO}_{2}(r=0.686)$ during the study period (Table 3).

We show the relationship between meteorological and air pollution variables and RR of HS stratified by sex and age group using univariate Poisson regression models (Tables 4 and 5). The mean temperature correlated negatively with HS in the older age group. We also observed a negative correlation between $\mathrm{ICH}$ and mean temperature, with a more significant negative correlation in the older age group. On the other hand, there was no significant correlation between mean temperature and SAH. Atmospheric pressure showed a positive correlation with $\mathrm{ICH}$ in the older age group. Insolation was positively correlated with SAH in the younger age group, and humidity showed a negative correlation with $\mathrm{ICH}$ in the older age group. Among the air pollution variables, $\mathrm{PM}_{10}$ was positively correlated with $\mathrm{HS}$, and both $\mathrm{PM}_{10}$ and $\mathrm{NO}_{2}$ showed strong positive correlations with $\mathrm{ICH}$, especially in the older age group. However, $\mathrm{PM}_{10}$ and $\mathrm{NO}_{2}$ showed no significant correlation with SAH. In contrast, $\mathrm{O}_{3}$ correlated significantly with $\mathrm{SAH}$, particularly in the younger age group.

Figures 1 and 2 show the RR of ICH and SAH occurrence with $95 \%$ CIs from multivariate Poisson regression after adjusting for all meteorological factors and pollutants. Among all meteorological and air pollution variables, $\mathrm{PM}_{10}$ was independently correlated with $\mathrm{ICH}$ occurrence (RR, 1.09; $95 \% \mathrm{CI}, 1.02$ to $1.15 ; P=0.012$ per $10-\mu \mathrm{g} / \mathrm{m}^{3}$ increment) and $\mathrm{O}_{3}$ was associated with SAH occurrence (RR, 1.32; $95 \% \mathrm{CI}, 1.10$ to $1.58 ; P=$ 0.003 per 10 -ppb increment).

\section{Discussion}

The present study showed a correlation between a lower mean temperature, higher concentration of $\mathrm{PM}_{10}$ or $\mathrm{NO}_{2}$ with a higher incidence of $\mathrm{ICH}$, especially in the older age group. Lower humidity and higher atmospheric pressure correlated with a higher incidence of ICH in the older age group, and insolation was associated with $\mathrm{SAH}$ in the younger age group. In addition, $\mathrm{O}_{3}$ showed a positive correlation with SAH incidence. In the multivariate analysis, $\mathrm{PM}_{10}$ associated independently with $\mathrm{ICH}$ occurrence and $\mathrm{O}_{3}$ was correlated independently with $\mathrm{SAH}$ occurrence among all meteorological and air pollution variables.

Table 1 Baseline characteristics of patients with first-ever hemorrhagic stroke in the Seongdong District, Seoul, Korea, 2004-2014

\begin{tabular}{|c|c|c|c|c|}
\hline \multirow[b]{2}{*}{ Characteristics } & \multicolumn{3}{|c|}{$\begin{array}{l}\text { Seongdong district, Seoul, Population }{ }^{a} \\
n=248,996\end{array}$} & \multirow[b]{2}{*}{$P$} \\
\hline & $\begin{array}{l}\mathrm{HS} \\
n=1,477\end{array}$ & $\begin{array}{l}\mathrm{ICH} \\
n=1,016\end{array}$ & $\begin{array}{l}\text { SAH } \\
n=461\end{array}$ & \\
\hline \multicolumn{5}{|l|}{ Age, yr } \\
\hline Mean (SD) & $57.2(14.1)$ & $57.3(14.5)$ & $57.0(13.3)$ & $0.767^{b}$ \\
\hline$<60$ years, $n(\%)$ & $859(59.2)$ & $582(57.3)$ & $277(60.1)$ & $0.333^{c}$ \\
\hline \multicolumn{5}{|l|}{ Sex } \\
\hline Male, $n(\%)$ & $801(54.2)$ & $640(63.0)$ & $161(34.9)$ & $<0.001^{\mathrm{C}}$ \\
\hline \multicolumn{5}{|l|}{ History of risk factors } \\
\hline Hypertension, n (\%) & $750(50.8)$ & $509(50.1)$ & $241(52.3)$ & $0.465^{c}$ \\
\hline Diabetes mellitus, $n$ (\%) & $208(14.1)$ & $156(15.4)$ & $52(11.3)$ & $0.043^{c}$ \\
\hline Drinking alcohol, $n$ (\%) & $552(37.4)$ & $432(42.5)$ & $120(26.0)$ & $<0.001^{\mathrm{C}}$ \\
\hline Smoking, $n(\%)$ & $384(26.0)$ & $294(28.9)$ & $90(19.5)$ & $<0.001^{\mathrm{C}}$ \\
\hline
\end{tabular}

${ }^{\mathrm{a}}$ Data are based on the population census of Korea for the year 2014

$b_{\text {t-test }}$

${ }^{c} \mathrm{X}^{2}$-test respectively 
Table 2 Descriptive analysis of monthly hemorrhagic stroke occurrence and average monthly meteorological and air pollution factors

\begin{tabular}{|c|c|c|c|c|c|c|c|c|c|c|}
\hline Month & $\mathrm{HS}, n(\%)$ & $\mathrm{ICH}, n(\%)$ & $\mathrm{SAH}, n(\%)$ & Mean temperature $\left({ }^{\circ} \mathrm{C}\right)$ & $\begin{array}{l}\text { Atmospheric } \\
\text { pressure (hPa) }\end{array}$ & Humidity (\%) & $\begin{array}{l}\text { Insolation } \\
\text { (hour) }\end{array}$ & $\begin{array}{l}\mathrm{PM}_{10} \\
\left(\mu \mathrm{g} / \mathrm{m}^{3}\right)\end{array}$ & $\begin{array}{l}\mathrm{NO}_{2} \\
\text { (ppb) }\end{array}$ & $\begin{array}{l}\mathrm{O}_{3} \\
\text { (ppb) }\end{array}$ \\
\hline Jan & $141(9.5)$ & $106(10.4)$ & $35(7.6)$ & -3.7 & 1015.3 & 51.3 & 6.4 & 62.3 & 41.6 & 10.9 \\
\hline Feb & $122(8.3)$ & $95(9.4)$ & $27(5.9)$ & 0.9 & 1014.7 & 50.2 & 6.1 & 62.2 & 38.5 & 13.9 \\
\hline Mar & $131(8.9)$ & $77(7.6)$ & $54(11.7)$ & 5.2 & 1008.3 & 51.7 & 6.5 & 62.0 & 35.9 & 21.3 \\
\hline Apr & $134(9.1)$ & $93(9.2)$ & $41(8.9)$ & 11.0 & 1004.1 & 49.9 & 7.4 & 64.2 & 37.0 & 28.7 \\
\hline May & $145(9.8)$ & $91(9.0)$ & $54(11.7)$ & 17.9 & 1000.6 & 56.2 & 6.7 & 62.1 & 33.7 & 30.6 \\
\hline Jun & $107(7.2)$ & $74(7.3)$ & $33(7.2)$ & 23.1 & 997.5 & 61.7 & 6.5 & 43.8 & 29.1 & 31.1 \\
\hline Jul & $103(7.0)$ & $70(6.9)$ & $33(7.2)$ & 24.6 & 996.0 & 79.1 & 4.1 & 38.4 & 25.1 & 21.6 \\
\hline Aug & $117(7.9)$ & $80(7.9)$ & $37(8.0)$ & 26.5 & 998.3 & 72.0 & 4.4 & 29.4 & 21.8 & 23.2 \\
\hline Sep & $121(8.2)$ & $90(8.9)$ & $31(6.7)$ & 21.8 & 1004.2 & 64.2 & 5.3 & 32.2 & 25.9 & 19.4 \\
\hline Oct & $112(7.6)$ & $66(6.5)$ & $46(10.0)$ & 15.7 & 1009.0 & 59.9 & 7.3 & 42.0 & 32.6 & 14.6 \\
\hline Nov & $126(8.5)$ & $87(8.6)$ & $39(8.5)$ & 6.7 & 1010.9 & 57.1 & 5.8 & 49.3 & 35.2 & 12.1 \\
\hline Dec & $118(8.0)$ & $87(8.6)$ & $31(6.7)$ & 0.2 & 1014.1 & 56.4 & 5.2 & 61.0 & 39.4 & 9.6 \\
\hline
\end{tabular}

$\mathrm{HS}$ Hemorrhagic stroke, $I \mathrm{CH}$, Intracerebral hemorrhage, $\mathrm{SAH}$ Subarachnoid hemorrhage, $\mathrm{PM}_{10}$ Particulate matter less than $10 \mathrm{~mm}$ in aerodynamic diameter, $\mathrm{NO}_{2}$, Nitrogen dioxide, $\mathrm{O}_{3}$, Ozone

Many studies have investigated the association between air temperature or season and HS incidence, $[1,3-10,17,18]$ and most have demonstrated that the incidence of $\mathrm{ICH}$ increases at lower temperatures or during colder seasons [1, 3-10]. A study in Korea [3] described a correlation between higher incidence of $\mathrm{ICH}$ and lower temperature and higher atmospheric pressure in an older age group. These findings are similar to ours. In contrast with $\mathrm{ICH}$, there have been inconsistent findings regarding the relationship between air temperature and SAH incidence. Several authors $[1,17,19,20]$ indicated that colder daily temperatures were associated with an increased risk of SAH. On the other hand, more recent studies reported that no relationship was observed between temperature changes and the occurrence of SAH [4, 18, 21-23].

In the present study, atmospheric pressure showed a positive correlation with $\mathrm{ICH}$ incidence, and humidity correlated negatively with $\mathrm{ICH}$ incidence in the old age group. However, meteorological parameters are closely related to one another. In our study, mean temperature showed the strongest negative correlation with atmospheric pressure and a weak positive correlation with humidity. According to Gay-Lussac's Law, atmospheric pressure is dependent on air temperature. In addition, about $60 \%$ of the annual precipitation occurs during the summer (June to August) in Seoul, Korea. Therefore, we assume that the changes in incidence of $\mathrm{ICH}$ associated with atmospheric pressure and humidity are attributable to the primary effect of changes in temperature.

Associations also exist among pollutants and between meteorological factors and pollutants. In the present study, there was a moderately strong association between $\mathrm{PM}_{10}$ and $\mathrm{NO}_{2}$, and the mean temperature showed a moderate negative correlation with $\mathrm{PM}_{10}$ and $\mathrm{NO}_{2}$. Xiang et al. [13] explained that the main reasons for higher air pollution levels at cold temperatures are air stagnation by light wind and lack of precipitation and

Table 3 Pearson correlation coefficients among weather variables and pollutants

\begin{tabular}{|c|c|c|c|c|c|c|c|}
\hline & $\begin{array}{l}\text { Mean temperature } \\
\left({ }^{\circ} \mathrm{C}\right)\end{array}$ & $\begin{array}{l}\text { Atmospheric pressure } \\
(\mathrm{hPa})\end{array}$ & Humidity (\%) & $\begin{array}{l}\text { Insolation } \\
\text { (hours) }\end{array}$ & $\begin{array}{l}\mathrm{PM}_{10} \\
\left(\mu \mathrm{g} / \mathrm{m}^{3}\right)\end{array}$ & $\begin{array}{l}\mathrm{NO}_{2} \\
(\mathrm{ppb}) \\
\end{array}$ & $\begin{array}{l}\mathrm{O}_{3} \\
\text { (ppb) }\end{array}$ \\
\hline Mean temperature $\left({ }^{\circ} \mathrm{C}\right)$ & 1 & $-0.824^{*}$ & $0.419^{*}$ & $-0.123^{*}$ & $-0.587^{*}$ & $-0.589^{*}$ & $0.346^{*}$ \\
\hline Atmospheric pressure $(\mathrm{hPa})$ & & 1 & $-.0368^{*}$ & $0.087^{*}$ & $0.411^{*}$ & $0.582^{*}$ & $-0.502^{*}$ \\
\hline Humidity (\%) & & & 1 & $-0.603^{*}$ & $-0.312^{*}$ & $-0.348^{*}$ & 0.047 \\
\hline Insolation (hours) & & & & 1 & $0.086^{*}$ & $0.122^{*}$ & $0.231^{*}$ \\
\hline $\mathrm{PM}_{10}\left(\mu \mathrm{g} / \mathrm{m}^{3}\right)$ & & & & & 1 & $0.686^{*}$ & -0.038 \\
\hline $\mathrm{NO}_{2}(\mathrm{ppb})$ & & & & & & 1 & $-0.463^{*}$ \\
\hline $\mathrm{O}_{3}(\mathrm{ppb})$ & & & & & & & 1 \\
\hline
\end{tabular}

$P M_{10}$, Particulate matter less than $10 \mathrm{~mm}$ in aerodynamic diameter, $\mathrm{NO}_{2}$ Nitrogen dioxide, $\mathrm{O}_{3}$ Ozone ${ }^{*} P<0.001$ 
Table 4 Relative risk of hemorrhagic stroke stratified by sex and age group, based on meteorological factors

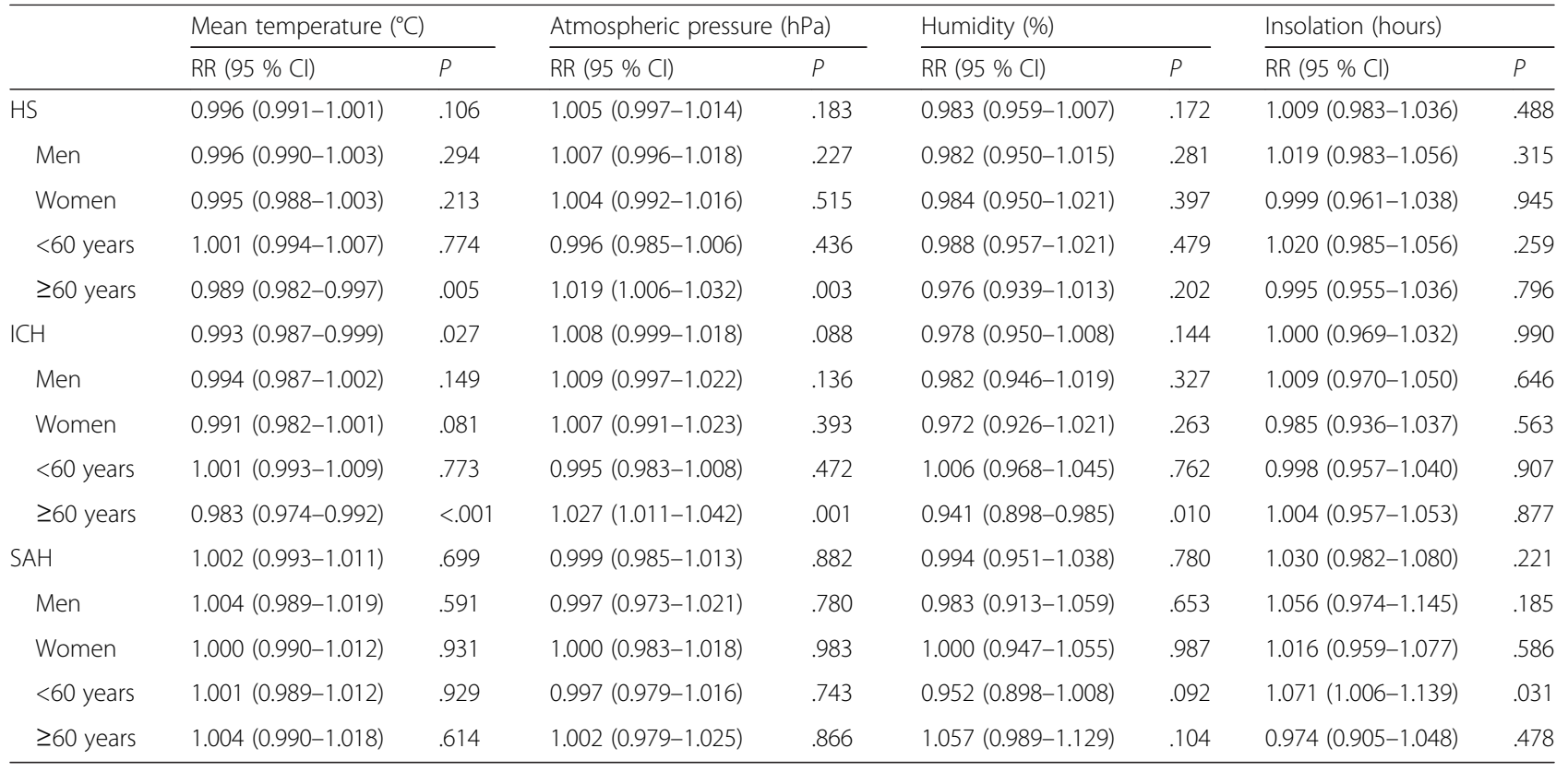

HS Hemorrhagic stroke, ICH Intracerebral hemorrhage, SAH Subarachnoid hemorrhage, RR Relative risk, $\mathrm{Cl}$ Confidence interval

formation of inversion layer. These conditions make it hard for air-suspended particles to diffuse to high altitude. A recent study [13] conducted during the colder seasons showed that $\mathrm{PM}_{10}$ and $\mathrm{NO}_{2}$ were significantly associated with an increase in stroke admissions.

In our study, $\mathrm{PM}_{10}$ and cold temperatures showed a significant association with ICH admissions. Exposure to cold can cause an increase in blood pressure and heart rate, $[1,4,5,7,10]$ especially in elderly individuals because they experience a greater increase in blood pressure after superficial skin cooling, [24, 25] as shown by our results. In people without vascular disease these effects might cause no harm, but they could predispose older patients with vascular disease to ICH [26]. In addition, laboratory findings suggest that exposure to fine particles can increase blood pressure [27], and

Table $\mathbf{5}$ Relative risk of hemorrhagic stroke stratified by sex and age group, based on pollutants

\begin{tabular}{|c|c|c|c|c|c|c|}
\hline & $\mathrm{PM}_{10}\left(\mu \mathrm{g} / \mathrm{m}^{3}\right)$ & & $\mathrm{NO}_{2}(\mathrm{ppb})$ & & $\mathrm{O}_{3}(\mathrm{ppb})$ & \\
\hline & $\overline{\mathrm{RR}}(95 \% \mathrm{Cl})$ & $P$ & $\overline{R R}(95 \% \mathrm{Cl})$ & $P$ & $\overline{\mathrm{RR}}(95 \% \mathrm{Cl})$ & $P$ \\
\hline$\overline{\mathrm{HS}}$ & $1.053(1.017-1.091)$ & .003 & $1.060(0.984-1.143)$ & .126 & $1.079(1.013-1.150)$ & .018 \\
\hline Men & $1.053(1.005-1.104)$ & .031 & 1.079 (0.975-1.194) & .143 & 1.046 (0.959-1.139) & .310 \\
\hline Women & $1.053(1.000-1.109)$ & .048 & $1.038(0.929-1.160)$ & .510 & $1.121(1.021-1.231)$ & .017 \\
\hline$<60$ years & $1.033(0.987-1.081)$ & .161 & $1.005(0.912-1.107)$ & .926 & $1.167(1.075-1.266)$ & $<.001$ \\
\hline$\geq 60$ years & $1.084(1.026-1.144)$ & .004 & 1.146 (1.019-1.290) & .023 & $0.962(0.870-1.064)$ & .454 \\
\hline $\mathrm{ICH}$ & $1.071(1.027-1.117)$ & .001 & $1.108(1.013-1.213)$ & .026 & 1.025 (0.949-1.106) & .530 \\
\hline Men & $1.063(1.008-1.120)$ & .023 & $1.123(1.002-1.258)$ & .047 & $1.006(0.913-1.108)$ & .908 \\
\hline Women & $1.085(1.013-1.162)$ & .019 & $1.085(0.936-1.257)$ & .280 & 1.057 (0.933-1.198) & .381 \\
\hline$<60$ years & $1.022(0.967-1.080)$ & .437 & $1.015(0.902-1.142)$ & .800 & $1.084(0.981-1.198)$ & .114 \\
\hline$\geq 60$ years & $1.143(1.071-1.219)$ & $<.001$ & $1.252(1.088-1.440)$ & .002 & $0.948(0.841-1.068)$ & .376 \\
\hline $\mathrm{SAH}$ & $1.014(0.952-1.080)$ & .667 & 0.959 (0.839-1.098) & .547 & 1.167 (1.059-1.286) & .002 \\
\hline Men & $1.016(0.916-1.127)$ & .765 & $0.926(0.742-1.157)$ & .500 & $1.240(1.054-1.460)$ & .010 \\
\hline Women & $1.013(0.936-1.096)$ & .754 & $0.979(0.827-1.160)$ & .809 & 1.129 (1.000-1.274) & .051 \\
\hline$<60$ years & $1.056(0.975-1.144)$ & .180 & $0.982(0.828-1.166)$ & .839 & $1.273(1.125-1.441)$ & $<.001$ \\
\hline$\geq 60$ years & $0.949(0.857-1.051)$ & .311 & $0.924(0.743-1.148)$ & .474 & $1.018(0.869-1.192)$ & .828 \\
\hline
\end{tabular}




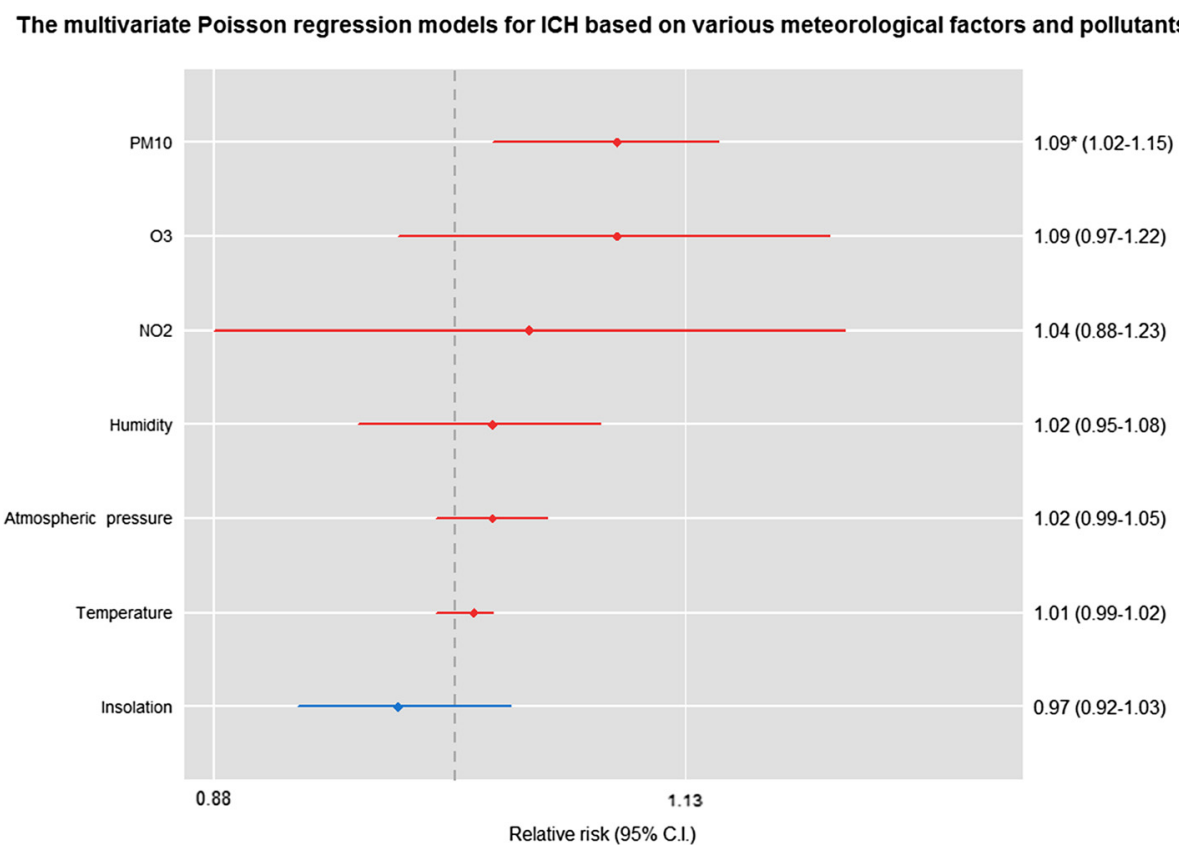

Fig. 1 Relative risk, $95 \%$ confidence interval and p-value for ICH occurrence, adjusted for all meteorological factors and pollutants, based on $1{ }^{\circ} \mathrm{C}$ increments in mean temperature, 1 - $\mathrm{hPa}$ increments in atmospheric pressure, $5 \%$ increments in humidity, 1-h increments in sun exposure and $10-\mu \mathrm{g} / \mathrm{m}^{3}$ or $10-\mathrm{ppb}$ increases in air pollutants

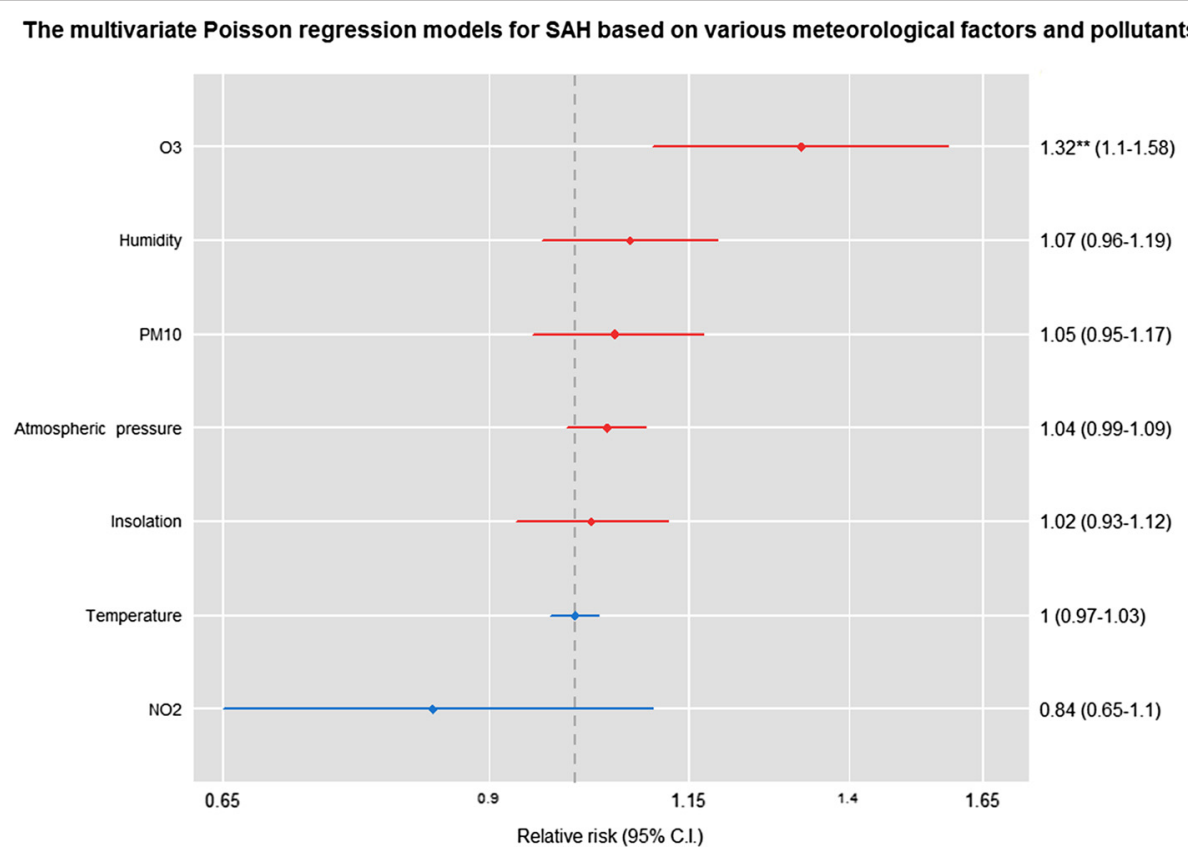

Fig. 2 Relative risk, $95 \%$ confidence intervals and $p$-values for SAH occurrence, adjusted for all meteorological factors and pollutants, based on $1{ }^{\circ} \mathrm{C}$ increments in mean temperature, 1-hPa increments in atmospheric pressure, $5 \%$ increments in humidity, 1-h increments in sun exposure and $10-\mu \mathrm{g} / \mathrm{m}^{3}$ or $10-\mathrm{ppb}$ increases in air pollutants 
several studies reported positive associations between the incidence of $\mathrm{HS}$ and $\mathrm{PM}_{10}$ and $\mathrm{NO}_{2}$ concentrations [11-15]. Yorifuji et al. [11] reported the potential mechanisms linking fine particles and $\mathrm{NO}_{2}$ to $\mathrm{HS}$. First, direct ischemic damage to blood vessels induced by fine particles and $\mathrm{NO}_{2}$ might lead to brain hemorrhage; second, fine particles and $\mathrm{NO}_{2}$ have been associated with acute endothelial dysfunction (atherosclerosis), which may lead to increased vulnerability of brain vessels to rupture; third, fine particles and $\mathrm{NO}_{2}$ may trigger vasoconstriction or hypertension, which might also lead to HS.

$\mathrm{O}_{3}$ was positively associated with $\mathrm{SAH}$ occurrence in our study. The ability of $\mathrm{O}_{3}$ to impair lung function and cause systemic inflammation has been reported in many studies [28-31]. Recently a prospective cohort study showed that low forced expiratory volume in one second (FEV1) or FEV1/forced vital capacity (FVC) is a risk factor for SAH independent of smoking [32]. The authors suggested that reduced lung function is associated with high levels of inflammatory markers and that the degree of local inflammation in intracranial aneurysmal walls might predict the risk of aneurysm rupture. In addition, both insolation and $\mathrm{O}_{3}$ were associated with $\mathrm{SAH}$ incidence in the younger age group. Younger individuals are far more likely to engage in strenuous outdoor activity than older individuals. Therefore, younger individuals have a naturally higher chance of being exposed to the sun and heat waves. The individuals younger than 60 years old might be more sensitive to develop SAH due to high $\mathrm{O}_{3}$ levels alone than individuals aged 60 years and over. The highest surface $\mathrm{O}_{3}$ concentrations occur mainly during seasons with the greatest insolation [33]. According to the Climate and Air Quality Management Division of South Korea, $\mathrm{O}_{3}$ is usually formed between 2 and 4 p.m. under conditions of low wind, high temperature and high insolation. Therefore, although the mechanism of interaction between $\mathrm{O}_{3}$ and insolation on $\mathrm{SAH}$ occurrence is unclear, we hypothesize that peak $\mathrm{O}_{3}$ due to high insolation or the combination $\mathrm{O}_{3}$ and insolation might have some effect on SAH occurrence.

Lastly, we calculated RR using a multivariate Poisson regression model to identify independent meteorological and air pollution variables associated with either ICH or $\mathrm{SAH}$ occurrence. $\mathrm{PM}_{10}$ was independently correlated with $\mathrm{ICH}$ occurrence and $\mathrm{O}_{3}$ was independently associated with SAH occurrence. Therefore, we hypothesized that ICH tends to be associated with hypertensive conditions, while SAH tends to correlate with inflammatory conditions.

There are several limitations and strengths to our single, hospital-based study.

Because this study was undertaken in a restricted region, the generalizability of these findings is limited. However, population characteristics, including exposure levels and socioeconomic factors, are likely to be more homogenous within small geographical areas [34]. Therefore, studies covering a large region have inevitable data inconsistency issues, as well as a lack of weather and environmental homogeneity. We think it is of value to determine the association between HS and meteorological factors and pollutants under similar weather and environmental conditions in the specific area of our study. In addition, the data quality, consistency and accuracy of our study are reliable because the authors were able to manage all data directly from the stroke registry of the department of neurosurgery at a single hospital.

Since we investigated average monthly weather, pollutant exposure and HS events, the results of this study cannot evaluate the short-term effects of daily variations in meteorological and air pollution parameters on HS incidence. However, long-term studies measuring the cumulative effects of chronic exposure to weather and air pollution, even at subacute levels, may provide information about the risk factors involved in the early and middle stages of the disease process [35].

\section{Conclusions}

Our findings show the relationship between HS and meteorological parameters and pollutants stratified by sex and age group. We found that, among the measured meteorological and pollutant variables, only higher $\mathrm{PM}_{10}$ concentrations correlated independently with $\mathrm{ICH}$ occurrence. Among the same variables, only $\mathrm{O}_{3}$ was independently associated with SAH occurrence. Our study supports the possibility that there are pathogenic associations between hemorrhagic stroke and meteorological factors and pollutants.

\section{Competing interests \\ The authors declare that they have no competing interests.}

\begin{abstract}
Authors' contributions
$\mathrm{MH}$ wrote this paper, performed statistical analyses, and collected and interpreted relevant data. HJ conceptualized and re-examined this paper. YK re-examined and revised this paper. YS re-examined this paper. YJ re-examined and confirmed the radiologic findings of this paper. All authors have read and approved the submitted manuscript; the manuscript has not been submitted elsewhere nor published elsewhere in whole or in part, except as an abstract (if relevant).
\end{abstract}

\section{Acknowledgements}

None

\section{Author details}

${ }^{1}$ Department of Neurosurgery, Hanyang University Medical Center, 222 Haengdang-ro, Seoul 133-792, South Korea. 'Department of Radiology, Hanyang University Medical Center, Seoul, South Korea.

Received: 12 August 2015 Accepted: 26 April 2016

Published online: 04 May 2016 


\section{References}

1. Park HS, Kang MJ, Huh JT. Recent Epidemiological Trends of Stroke. J Korean Neurosurg Soc. 2008;43:16.

2. Kitamura A, Nakagawa $Y$, Sato M, Iso H, Sato S, Imano H, et al. Proportions of Stroke Subtypes Among Men and Women $\geq 40$ Years of Age in an Urban Japanese City in 1992, 1997, and 2002. Stroke. 2006;37:1374-8.

3. Kim HJ, Kim JH, Kim DR, Kang HI, Moon BG, Kim JS. Age and meteorological factors in the occurrence of spontaneous intracerebral hemorrhage in a metropolitan city. J Cerebrovasc Endovasc Neurosurg. 2014;16:209-15.

4. Azevedo E, Ribeiro JA, Lopes F, Martins R, Barros H. Cold: a risk factor for stroke? J Neurol. 1995;242:217-21.

5. Turin TC, Kita Y, Murakami Y, Rumana N, Sugihara H, Morita Y, et al. Higher Stroke Incidence in the Spring Season Regardless of Conventional Risk Factors Takashima Stroke Registry, Japan, 1988-2001. Stroke. 2008;39:745-52.

6. Shinkawa A, Ueda K, Hasuo Y, Kiyohara Y, Fujishima M. Seasonal variation in stroke incidence in Hisayama, Japan. Stroke J Cereb Circ. 1990;21:1262-7.

7. Wang Y, Levi CR, Attia JR, D'Este CA, Spratt N, Fisher J. Seasonal Variation in Stroke in the Hunter Region, Australia A 5-Year Hospital-Based Study, 19952000. Stroke. 2003:34:1144-50.

8. Takizawa S, Shibata T, Takagi S, Kobayashi S. Seasonal Variation of Stroke Incidence in Japan for 35631 Stroke Patients in the Japanese Standard Stroke Registry, 1998-2007. J Stroke Cerebrovasc Dis. 2013;22:36-41.

9. Palm F, Santos MD, Urbanek C, Greulich M, Zimmer K, Safer A, et al. Stroke seasonality associations with subtype, etiology and laboratory results in the Ludwigshafen Stroke Study (LuSSt). Eur J Epidemiol. 2013;28:373-81.

10. Jimenez-conde J, Ois A, Gomis M, Rodriguez-Campello A, Cuadrado-Godia E, Subirana I, et al. Weather as a Trigger of Stroke. Cerebrovasc Dis. 2008;26:348-54.

11. Yorifuji T, Kawachi I, Sakamoto T, Doi H. Associations of outdoor air pollution with hemorrhagic stroke mortality. J Occup Environ Med Am Coll Occup Environ Med. 2011:53:124-6.

12. Tsai SS, Goggins WB, Chiu HF, Yang CY. Evidence for an association between air pollution and daily stroke admissions in Kaohsiung, Taiwan. Stroke J Cereb Circ. 2003;34:2612-6.

13. Xiang $H$, Mertz KJ, Arena VC, Brink LL, Xu X, Bi Y, et al. Estimation of shortterm effects of air pollution on stroke hospital admissions in Wuhan, China. PLoS One. 2013;8, e61168.

14. Yorifuji T, Kashima S, Tsuda T, Ishikawa-Takata K, Ohta T, Tsuruta K, et al. Long-term exposure to traffic-related air pollution and the risk of death from hemorrhagic stroke and lung cancer in Shizuoka, Japan. Sci Total Environ. 2013:443:397-402

15. Qian Y, Zhu M, Cai B, Yang Q, Kan H, Song G, et al. Epidemiological evidence on association between ambient air pollution and stroke mortality. J Epidemiol Community Health. 2013;67:635-40.

16. Han MH, Yi HJ, Kim YS, Kim YS. Effect of Seasonal and Monthly Variation in Weather and Air Pollution Factors on Stroke Incidence in Seoul, Korea. Stroke. 2015;46:927-35.

17. Gill RS, Hambridge HL, Schneider EB, Hanff T, Tamargo RJ, Nyquist P. Falling Temperature and Colder Weather Are Associated with an Increased Risk of Aneurysmal Subarachnoid Hemorrhage. World Neurosurg. 2013;79:136-42.

18. McDonald RJ, McDonald JS, Bida JP, Kallmes DF, Cloft HJ. Subarachnoid Hemorrhage Incidence in the United States Does Not Vary with Season or Temperature. Am J Neuroradiol. 2012;33:1663-8.

19. Abe T, Ohde S, Ishimatsu S, Ogata H, Hasegawa T, Nakamura T, et al. Effects of meteorological factors on the onset of subarachnoid hemorrhage: a timeseries analysis. J Clin Neurosci Off J Neurosurg Soc Australas. 2008:15:1005-10.

20. Law HY, Wong GKC, Chan DTM, Wong L, Poon WS. Meteorological factors and aneurysmal subarachnoid haemorrhage in Hong Kong. Hong Kong Med. J Xianggang Yi Xue Za Zhi Hong Kong Acad Med. 2009;15:85-9.

21. Rué M, Camiade $\mathrm{E}$, Jecko V, Bauduer F, Vignes JR. The relationship between aneurysmal subarachnoid hemorrhage and meteorological parameters based on a series of 236 French patients. Neurochirurgie. 2014:60:222-6.

22. Lai PMR, Dasenbrock H, Du R. The Association between Meteorological Parameters and Aneurysmal Subarachnoid Hemorrhage: A Nationwide Analysis. PLoS One. 2014;9:e 112961.

23. Cowperthwaite MC, Burnett MG. The association between weather and spontaneous subarachnoid hemorrhage: an analysis of 155 US hospitals. Neurosurgery. 2011;68:132-8. discussion 138-139.

24. Hess KL, Wilson TE, Sauder CL, Gao Z, Ray CA, Monahan KD. Aging affects the cardiovascular responses to cold stress in humans. J Appl Physiol 1985 2009:107:1076-82
25. Keatinge WR, Coleshaw SR, Cotter F, Mattock M, Murphy M, Chelliah R. Increases in platelet and red cell counts, blood viscosity, and arterial pressure during mild surface cooling: factors in mortality from coronary and cerebral thrombosis in winter. Br Med J (Clin Res Ed). 1984;289:1405-8.

26. Berginer VM, Goldsmith J, Batz U, Vardi H, Shapiro Y. Clustering of strokes in association with meteorologic factors in the Negev Desert of Israel: 19811983. Stroke. 1989:20:65-9.

27. Chang C-C, Hwang J-S, Chan C-C, Wang PY, Hu TH, Cheng TJ. Effects of concentrated ambient particles on heart rate, blood pressure, and cardiac contractility in spontaneously hypertensive rats. Inhal Toxicol. 2004;16:421-9.

28. Kahle JJ, Neas LM, Devlin RB, et al. Interaction Effects of Temperature and Ozone on Lung Function and Markers of Systemic Inflammation, Coagulation, and Fibrinolysis: A Crossover Study of Healthy Young Volunteers. Environ Health Perspect. 2014;10, e1307986.

29. Carlsen HK, Forsberg B, Meister K, Gíslason T, Oudin A. Ozone is associated with cardiopulmonary and stroke emergency hospital visits in Reykjavík, celand 2003-2009. Environ Health Glob Access Sci Source. 2013:12:28.

30. Sunil VR, Francis M, Vayas KN, Cervelli JA, Choi H, Laskin JD, et al. Regulation of ozone-induced lung inflammation and injury by the $\beta$-galactosidebinding lectin galectin-3. Toxicol Appl Pharmacol. 2015:284:236-45.

31. Henrotin JB, Besancenot JP, Bejot Y, Giroud M. Short-term effects of ozone air pollution on ischaemic stroke occurrence: a case-crossover analysis from a 10-year population-based study in Dijon, France. Occup Environ Med. 2007:64:439-45.

32. Söderholm M, Zia E, Hedblad B, Engström G. Lung Function as a Risk Factor for Subarachnoid Hemorrhage A Prospective Cohort Study. Stroke. 2012 43:2598-603.

33. Castell N, Mantilla E, Millan MM. Analysis of tropospheric ozone concentration on a Western Mediterranean site: Castellon (Spain). Environ Monit Assess. 2008;136:3-11.

34. Maheswaran R, Haining RP, Brindley P, Law J, Pearson T, Fryers PR, et al. Outdoor air pollution and stroke in Sheffield, United Kingdom: a small-area level geographical study. Stroke J Cereb Circ. 2005:36:239-43.

35. Johnson JYM, Rowe BH, Villeneuve PJ. Ecological analysis of long-term exposure to ambient air pollution and the incidence of stroke in Edmonton, Alberta, Canada. Stroke J Cereb Circ. 2010;41:1319-25.

\section{Submit your next manuscript to BioMed Central and we will help you at every step:}

- We accept pre-submission inquiries

- Our selector tool helps you to find the most relevant journal

- We provide round the clock customer support

- Convenient online submission

- Thorough peer review

- Inclusion in PubMed and all major indexing services

- Maximum visibility for your research

Submit your manuscript at www.biomedcentral.com/submit 